\title{
An Analysis of the Associations between Ambiguity Tolerance and EFL Reading Strategy Awareness
}

\author{
Saeedeh Karbalaee Kamran (Corresponding author) \\ Department of English Language Teaching, Science and Research Branch, Islamic Azad University, Tehran, Iran \\ Laleh Junction, Janatabad-e-Jonoobi, Tehran, Iran \\ Tel: 98-21-4440-6048Ｅ-mail: saeedehkamran@gmail.com
}

Parviz Maftoon (Ph.D)

Department of English Language Teaching, Science and Research Branch, Islamic Azad University, Tehran, Iran

Tel: 98-21-4440-6048 E-mail: pmaftoon@gmail.com

Received: October 30, 2011

Accepted: November 30, 2011

Published: March 1, 2012

doi:10.5539/elt.v5n3p188

URL: http://dx.doi.org/10.5539/elt.v5n3p188

\begin{abstract}
The current study is an attempt to investigate whether any statistically significant relationship existed between Iranian EFL learners' ambiguity tolerance (AT) and their reading strategy use. To this end, three instruments of Survey of Reading Strategy (Mokhtari \& Sheorey, 2002), Second Language Ambiguity Tolerance Scale (Ely, 1995), and a reading test were administered to 114 (60 female and 54 male) intermediate level EFL learners of Iran Language Institute. The results of data analyses indicated that no statistically significant relationship existed between participants' AT and their overall reading strategy use. Also no statistically significant relationship existed between participants' AT and their use of Global, Problem Solving, and Support subscales of reading strategy. Further, the results revealed a statistically significant and positive relationship between AT and reading comprehension scores of the participants. Regarding findings of the study, pedagogical implications were presented for teachers and materials developers in the field of EFL teaching/learning.
\end{abstract}

Keywords: Ambiguity tolerance, Reading strategy, Metacognitive awareness, Reading comprehension, EFL learners

\section{Introduction}

Language learning is a matter of having the ability to deal with unknown and even vague features of a new language, and the one who owns the ability of such adaptation and tolerance is predicted to become a successful language learner. Rubin (1975) characterizes the good language learner as the one who is often not inhibited and who is willing to make mistakes in order to learn and to communicate, and who is willing to live with a certain amount of vagueness. Brown (2000), states that ambiguity tolerance (AT) is "the degree to which you are cognitively willing to tolerate ideas and propositions that run counter to your own belief system or structure of knowledge" (p. 119). According to Furnham (1994), tolerance for ambiguity refers to the way an individual (or group) considers and deals with information about ambiguous situations when they encounter a range of unfamiliar, complex or incongruent cues. AT is a variable which is often conceived of as a unidimensional scale: "the person with low tolerance of ambiguity supposedly experiences stress, reacts prematurely and avoids ambiguous stimuli. At the other extreme of the scale; however, a person with high tolerance for ambiguity perceives ambiguous situations/stimuli as desirable, challenging and interesting" (p. 403). Budner (1962) maintains that ambiguous situations can be of three different types: new situations; where cues are either absent or inadequate, complex situations; where too many cues are available, and contradictory situations; where different cues impose different interpretations. Similarly, Naiman, Frohlich, Stern, \& Todesco (1978) characterize ambiguous situation by "novelty, complexity, or insolubility, and further characterizes responses to such threatening situations by expressions of dislike, depression, attending to avoiding the situation, or by destructive behavior" (p. 70). Ely (1989) also emphasizes the nature of uncertainty in language learning context by stating that ambiguity in language learning is visualized by uncertainty, which is observed in many occasions when learners are not sure about the exact meaning of a new vocabulary item or an idiom, when they get confused by different uses of a grammatical tense, or when they feel that they have not pronounced a sound accurately. It sounds common as teachers have experienced situations in which learners cannot tolerate the first moments of encountering new structures, vocabulary items, or even cultural aspects of a new 
language. Such intolerance can negatively influence learners' performance as stress and agitation can block the way to retrieval of knowledge, or application of strategies. As White (1999) emphasizes, ambiguity, if is not tolerated reasonably, can involve learners in a stressful situation in which language learning, risk taking, and application of the appropriate strategies may be negatively influenced, or "deteriorated" (p. 456).

Regarding ambiguity tolerance as one of the important learning styles, which can impede or facilitate language learning, and use of language learning strategies, the investigation into possible relationships between degree of ambiguity tolerance, and utilization of different strategies is expected to provide fruitful results. Several studies on different aspects of ambiguity tolerance and its influence on language learning have been conducted in past years (Chappelle, 1983; El-Koumy, 2000; Erten \& Topkaya, 2009; Kazamia, 1999; Khajeh 2002; Liu, 2006). Studies on language learning strategies have gained floor, as they are regarded to play an important role in helping learners to have better language learning achievements. As Cohen (2003) states, language learning strategies are the conscious or semi-conscious thoughts and behaviors used by learners with the explicit goal of improving their knowledge and understanding of a target language. Therefore, any factor that enhances the use of learning strategies is beneficial to learning career. Regarding the large amount of input (in the form of reading texts) to which English language learners, especially English as a foreign language (EFL) learners, are exposed during any stage of language learning, it is expected that learning a foreign or second language be facilitated by learners' improvement in reading skill. Urquhart and Weir (1998) maintain that "reading is the process of receiving and interpreting information encoded in language form via the medium of print" (p. 22), and in traditional English Language classroom, it is considered as the most emphasized skill (Susser \& Robb, 1990). Similarly, Anderson (2003) considers reading as "an essential skill which is the most important skill to master for most of the learners of English in order to ensure success in learning" (p. 2).

Exploitation of reading strategies, as a way of enhancing reading comprehension, has received remarkable attention in past decades. Macaro (2003) defines reading strategies as cognitive and metacognitive actions that individuals use consciously or automatically when trying to access a text. Factors influencing the use of reading strategies deserve investigations, as improvement in reading skill plays a vital role in language learning process. Ambiguity tolerance, as a learning style, can influence the use of strategies and then language learning experience. Although no study was found to explore the relationship between AT and reading strategy use, in the past two decades, several studies have been carried out to shed light on different dimensions of the relationship between ambiguity tolerance and language learners' proficiency level, use of language learning strategies, and performance on reading comprehension or listening.

\section{Background of the Study}

The first study on AT, in the academic field of language learning was conducted in 1978. In a study on high school learners of French as a foreign language in Toronto, Naiman et al. (1978) found that, "when a learner was tolerant of ambiguity, he/she also wanted the teacher to use more foreign language (French), and was not ethnocentric" (p. 128). Later, Chapelle (1983) conducted her doctoral dissertation, on investigating the relationship between AT and the success in acquiring English as a second language in adult learners, in University of Illinois. The results of her study indicated the correlations between AT and beginning of semester language scores were not significant, but correlations between AT and end-of-semester scores, in multiple choice grammar test, dictation, and parts of a speaking test, were significantly positive.

Another researcher, Yea-Fen(1995), investigated the language learning strategies used by beginning students of Chinese in a semi-immersion setting, found that, success in learning was attributed to tolerance of ambiguity, use of strategies appropriate to the given task, and positive social and academic reinforcement. This study combined qualitative and quantitative methods to explore the learning strategies of 13 American college students taking first-year Chinese in a semi-immersion setting. The researcher employed several methods to gather data from students: interviews, observation, case studies, and a survey (Strategy Inventory for Language Learning, the SILL, adapted from Oxford, 1989). To ensure the accuracy of the data and its interpretation, prolonged engagement, triangulation, peer debriefing, and member checking were used.

Jun-yong (1998) explored patterns of language learning strategies and the degree of tolerance of ambiguity of Korean Naval Academy midshipmen. The subjects, 377 midshipmen, were divided into three groups according to class, discipline, and proficiency and the results were analyzed by group. The study also sought to find out relationships between motivation, attitude, language learning strategies, and tolerance of ambiguity through administration of the Strategy Inventory Language Learning (SILL for ESL/EFL) developed by Oxford (1990) and the SLATS developed by Ely (1995), along with items about motivation and attitude toward language learning.

It was found that the language learning strategy mean and tolerance of ambiguity mean were not high overall. The 
proficiency levels showed significant mean differences: The high proficiency level students showed a significantly higher mean use of language learning strategies and tolerance of ambiguity than did the low and mid proficiency level students. The seniors' mean of tolerance of ambiguity was significantly higher than that of the other class levels. There were no significant differences in the use of language learning strategies and tolerance of ambiguity across disciplines. Correlations between tolerance of ambiguity and language learning strategies were significant and positive, although modest.

Kazamia (1999) aimed to identify and assess the degree of ambiguity tolerance of Greek civil servants when learning English as a foreign language. The subjects who participated in the study are all Greek working in the Greek civil service. This sample, 323 participants, was drawn from six language course levels starting from the pre-intermediate level while the highest level is post proficiency, which is almost equivalent to Cambridge Proficiency in English (CPE). However, tolerance of ambiguity varies, depending on skills and language learning situations. On the other hand, learners cannot tolerate the ambiguities produced by their failure to express adequately their ideas in writing and speaking. This situation triggers a considerable amount of intolerance that might impede their progress in these skills.

Another study, conducted by El-Koumy (2000), examined the differences in foreign language reading comprehension among high, middle, and low AT students, who were 150 EFL learners, randomly drawn from all freshmen enrolled in the English section of four schools of education in Egypt. The results showed that the moderate AT group scored significantly higher than the low and high group.

Khajeh (2002) conducted a study on the relationship between AT and language proficiency, and language learning strategies. She reported that a positive correlation existed between AT and both proficiency level and frequency of strategy use. Participants were 120 male and female sophomores majoring in English with an age range of 18-25.

A study to find the relationship between AT and English for Science and Technology (EST) reading comprehension scores of 202 students of three disciplines of engineering was conducted by Hadiani (2005), as an MA thesis in Iran University of Science and Technology. She stated that, subjects with high ambiguity tolerance performed better in reading comprehension, and no significant correlation was found between disciplines and reading comprehension scores of industrial, railway, and computer engineering students.

Liu (2006) investigated the level of AT among 115 freshmen in Shandong University of Technology who were just finishing their first year in college. The findings, using SLATS, indicated that learners could not tolerate the ambiguities produced by their failure to express adequately their ideas in writing and speaking.

A recent study by Erten and Topkaya (2009) in Turkey explored the tolerance of ambiguity of a group of tertiary level Turkish EFL learners at a state university in Turkey. In this study, 188 preparation year students were administered SLATS along with some demographic questions. A strong relationship between tolerance of ambiguity and perceived success in reading in a foreign language was identified, implying that the more tolerant the learners were of ambiguity, the more successful they could be in the reading process.

A study by Soleimani (2009) on the differences in listening scores of 90 high, middle, and low AT learners of EFL in two English language institutes in Bandar-Abbas, was completed as an MA thesis. The results indicated that learners with moderate AT achieved higher listening scores.

\section{Purpose of the Study}

As considered in the review of the previous related studies, AT, as an important learning style in language learning context, can influence learning strategy use in general and reading strategy use, in particular. Poor performance in reading may be attributed to low level of proficiency; however, it can be a result of harmful degree of ambiguity tolerance. Therefore, investigation into the relationship between ambiguity tolerance and reading strategy use can guide us to achieve a more realistic view of factors influencing EFL learners' use of reading strategies.

The current study aims to investigate whether any statistically significant relationship exists between Iranian EFL learners' ambiguity tolerance and their overall reading strategy use. To shed more light on subscales of reading strategies-- Global, Support, or Problem Solving reading strategies-- the study also examines whether any statistically significant relationship exists between Iranian EFL learners' ambiguity tolerance and their use of Global, Support, or Problem Solving reading strategies. Moreover, the current study tries to investigate whether there is any statistically significant relationship between Iranian EFL learners' ambiguity tolerance and their reading comprehension scores. To this end, five research questions were formulated.

\section{Methodology}

4.1 Research Questions and Null Hypotheses

1) Is there any statistically significant relationship between Iranian EFL learners' ambiguity tolerance and their 
overall reading strategy use?

2) Is there any statistically significant relationship between Iranian EFL learners' ambiguity tolerance and their Global reading strategy use?

3) Is there any statistically significant relationship between Iranian EFL learners' ambiguity tolerance and their Support reading strategy use?

4) Is there any statistically significant relationship between Iranian EFL learners' ambiguity tolerance and their Problem Solving reading strategy use?

5) Is there any statistically significant relationship between Iranian EFL learners' ambiguity tolerance and their reading comprehension scores?

H01: There is no statistically significant relationship between Iranian EFL learners' ambiguity tolerance and their overall reading strategy use.

H02: There is no statistically significant relationship between Iranian EFL learners' ambiguity tolerance and their Global reading strategy use.

H03: There is no statistically significant relationship between Iranian EFL learners' ambiguity tolerance and their Support reading strategy use.

H04: There is no statistically significant relationship between Iranian EFL learners' ambiguity tolerance and their Problem Solving reading strategy use.

H05: There is no statistically significant relationship between Iranian EFL learners' ambiguity tolerance and their reading comprehension scores.

\subsection{Participants and Setting}

Participants of the present study were 114 EFL learners of Iran Language Institute (ILI), which is affiliated with Iran's Ministry of Education. The sample consisted of 60 female participants (52.6\%), and 54 male participants (47.4\%). The age of the participants ranged from 14 to 50 years. Participants of current study were high school students, university students, or graduates, with different degrees in various disciplines--humanities, engineering, pure sciences, medicine, and art. The participants of current study were a homogenous sample of EFL learners, with respect to their English language proficiency level. The researcher decided to select students of intermediate level in ILI (who were attending term Intermediate 1), to respect homogeneity issues. All EFL learners in ILI are obliged to sit a written placement test when entering ILI, after which they are interviewed and placed in an appropriate level.

\subsection{Instrumentation}

The three instruments used in this study were: 1) a reading test, 2) Survey of Reading Strategy (SORS), and 3) Second Language Tolerance of Ambiguity Scale (SLATS).

Reading Test. Reading part of a past Preliminary English Test PET (December 2005), developed by University of Cambridge ESOL Examinations and available in Khalifa and Weir (2009) was considered as an appropriate instrument. The reading part of PET included 35 items, and it had to be answered in 45 minutes.

Survey of Reading Strategy (SORS). To measure participants' perceived use of reading strategies, Survey of Reading Strategy (SORS) developed by Mokhtari and Sheorey (2002) was used. According to Mokhtari and Sheorey (2002), SORS includes 30 items in three categories (subscales): Global Reading Strategies (GLOB), Problem Solving Strategies (PROB), and Support Strategies (SUP). The scoring procedure suggested by Mokhtari and Sheorey (2002), was used in the current study. SORS had 30 items with a 5 point Likert scale statements after each. The scoring had the following procedure: I never use it: 1 mark; I occasionally use it: 2 marks; I sometimes use it: 3 marks; I usually use it: 4 marks; I always use it: 5 marks. Minimum mark was 30 , and the maximum was 150 .SORS is originally designed in English; however, to eliminate any possible misunderstanding of the statements, it was translated into Persian by the researcher.

Second Language Tolerance of Ambiguity Scale (SLATS). To measure participants' AT in the current study, SLATS developed by Ely (1995) was used. It was the only questionnaire specially designed to measure AT in language learning context. SLATS is a 4-point Likert scale questionnaire, used with Likert scales of strongly agree, agree, disagree and strongly disagree. The scoring procedure used in current study was to assign one mark to strongly agree, two marks to agree, tree marks to disagree, and four marks to strongly disagree. The scores could vary from 12 to 48 , and the higher the mark, the higher was the AT of the participant. SLATS was originally designed in English; however, to eliminate any possible misunderstanding of the statements, it was translated into Persian by the researcher. 


\subsection{Procedure}

In the first step, SORS developed by Mokhtari and Sheorey (2002), and SLATS developed by Ely (1995) which were both originally designed in English, were translated into Persian by the researcher in order to eliminate any possible misunderstanding of the statements. The first draft of the translated SORS and SLATS were revised by the researcher and also one of the scholars in the field of TEFL. The final draft of translated SORS and SLATS were prepared and used in the current study to collect data on participants reading strategy use and AT respectively. Another step was selecting an appropriate reading test. As Farhady, Jafarpur, \& Birjandi (1994) mention, to assure that a passage which is selected to be included in a test be at the level of the students, readability formulas can be used. They further offer a useful procedure to do so. First, the average readability of a random sample of reading comprehension passages of participants' coursebook must be calculated through one of the readability formulas. Then, readability of each of the passages intended to be included in the test must be calculated through the same readability formula. Further, reading comprehension passages with readability levels of \pm standard deviation of the average readability of course book passages would be most likely appropriate to be included in the test. In the current study, Fog Index was used to calculate readability level of reading test and coursebook reading comprehension passages. As Fog Index Level of the three passages of the nominated reading test $(9.99,10.07,7.64)$ fall within the acceptable readability range (7.33- 10.29), the reading part of the past PET of December 2005 was selected as the reading test of the current study to measure participants' proficiency in reading.

\subsubsection{Pilot Study}

To examine the internal reliability of the research instruments, the translated SORS and SLATS and also the reading test were piloted. 34 EFL learners (18 girls and 16 boys) of intermediate level in ILI, who comprised a representative sample of the main study participants in pilot study. Concerning the internal reliability of the reading test, Kuder-Richardson Coefficient 21, was found to be .871. Also Cronbach's alpha internal consistency reliability of the translate SLATS and SORS were found .896 and .829 respectively. The results of reliability analyses of all three instruments were satisfactory regarding guidelines of Vogt (2007) who states that, "An alpha of .70 or higher is often considered satisfactory for most purposes" (p. 115).

\subsubsection{Main Study}

The instruments were distributed by the researcher in the class time among 268 students who were present in that session. Excluding incomplete answer sheets, 114 acceptable answer sheets were collected; among which 54 ones $(47.4 \%)$ belonged to male participants and 60 ones $(52.6 \%)$ belonged to female participants.

\section{Results}

To test null hypotheses 1-5, correlational analyses were executed to calculate the Pearson Correlation Coefficient. The results of the analyses are presented in this section. To test H01, a correlational analysis was run. As Table 1 shows, Pearson Correlation Coefficient between Iranian EFL learners' AT and their overall reading strategy use is found to be $(\mathrm{r}=-.041)$ at significance level of $(.663)$, which is not significant at $\mathrm{p}<.05$. Therefore, H01 is failed to be rejected, and it is revealed that there is no statistically significant relationship between AT and overall reading strategy use of Iranian EFL learners. In order to test H02, a correlational analysis was run. As Table 2 shows, Pearson Correlation Coefficient between Iranian EFL learners' AT and their Global reading strategy use is found to be $(r=.011)$ at significance level of $(.908)$, which is not significant at $\mathrm{p}<.05$. Hence, H02 is failed to be rejected, and it is concluded that there is no statistically significant relationship between AT and Global reading strategy use of Iranian EFL learners. In order to investigate H03, a correlational analysis was run. As Table 3 shows, Pearson Correlation Coefficient between Iranian EFL learners' AT and their Support reading strategy use is found to be $(r=$ - .130) at significance level of (.169), which is not significant at $\mathrm{p}<.05$. Therefore, H03 is failed to be rejected, and AT is proved not to have any statistically significant relationship with Support reading strategy use of Iranian EFL learners. To provide the answer to H04, a correlational analysis was run. As Table 4 shows, Pearson Correlation Coefficient between Iranian EFL learners' AT and their Problem Solving reading strategy use is found to be $(r=$ $-.004)$ at significance level of (.968), which is not significant at $p<.05$. Consequently, H04 failed to be rejected, and AT is found not to have any statistically significant relationship with Problem Solving reading strategy use of Iranian EFL learners. To examine H05, a Pearson Correlation analysis was run. As it is indicated in Table 5, the correlation between Iranian EFL learners' AT and their reading comprehension scores is found to be $(\mathrm{r}=.383)$ at significance level of (.000), which reveals a statistically significant and positive correlation. Hence, H05 is rejected at $\mathrm{p}<.01$ and it can be concluded that a statistically significant relationship exists between Iranian EFL learners' AT and their reading comprehension scores. It is inferred that the higher is the learner's tolerance of ambiguity, the higher is his/her score in reading comprehension.

With respect to finding of the current study, in which a statistically significant and positive correlation is indicated 
between EFL learners' AT and their reading comprehension score, it is implied that when ambiguity is tolerated, reading comprehension in an EFL context can be enhanced. As language learning context in general, and the activity of reading in a foreign language in particular, are abundant with novelty and ambiguous clues, it is expected that when ambiguity is tolerated reasonably, language learning and also reading comprehension be enhanced (Brown, 2000; Ely, 1989; White, 1999).

\section{Discussion}

This study investigated whether any statistically significant relationship between AT and overall reading strategy use of Iranian intermediate level EFL learners. The study also investigated whether any statistically significant relationship existed between participants' AT and their use of Global, Support, and Problem Solving subscales of reading strategies. Considering the findings of the study on research question one, as no statistically significant relationship exists, between AT and the overall reading strategy use of the participants, it is inferred that AT as an underlying learning style does not correlate with overall reading strategy use. Reasonable tolerance of ambiguity can improve language learning in general (Brown, 2000; Ely, 1989; White, 1999), and also positive correlations between AT and language learning strategy use are reported by Jun-yong (1998) and Khajeh (2002); however, when the relationship between tolerance of ambiguity and reading strategy use is regarded in particular, a significant correlation is not explored, between AT and reading strategy use of the participants in the current study. It is interpreted that, when reading strategy use is focused among language learning variables, no correlation is established between AT and overall reading strategy use. It is worth mentioning that, when SORS items are closely considered, only 4 items of 13,24, 27, and 28 were found to investigate the learner' interaction with ambiguous clues when reading. In other words, items of SORS, are mainly concerned with investigating EFL learners' "metacognitive awareness and perceived use of reading strategies (broadly defined here as mental plans, techniques, and actions taken while reading" (Mokhtari \& Sheory, 2002, p. 2).The strategies of SORS, only slightly deal with measuring readers' AT when encountering unknown, or vague elements in a text. Findings of the current study, which show no statistically significant relationship between AT and the overall reading strategy use of the participants, can be interpreted with respect to the perception that, SORS strategies are not largely concerned with the actions of the learners' which are related to their AT when reading. Although both ambiguity tolerance and use of reading strategies can influence language learning in general and reading comprehension in particular, they seem to have different channels to direct their influence. Regarding the results of the study on research question two, no statistically significant relationship exists, between AT and the Global reading strategy use of the participants. As Mokhtari and Sheorey (2002) define, Global reading strategies are "intentional, carefully planned techniques by which learners monitor or manage their reading" (p. 4), for example, having a purpose in mind when reading, thinking about ones background knowledge, having overall view of the text before reading, using context clues, typographical features, tables, and pictures to better understand the text, etc. When 13 items of Global reading strategies, are closely considered, it is perceived that these strategies are mostly techniques which help readers to have a general evaluation and comprehension of the text. As item 24 and 27of SORS, are respectively concerned with guessing the content of the text when reading, and checking the verity of such guesses (Mokhtari \& Sheorey, 2002), they were found the only strategies which investigate the readers' interaction with ambiguous clues when reading. In other words, items of Global reading strategies in SORS are concerned with measuring readers' use of techniques which help them have a general evaluation and understanding of the text, and these strategies, only slightly deal with measuring readers' AT when encountering unknown, or vague elements in a text. Regarding the findings of research question three, it is revealed that AT does not indicate a statistically significant relationship with Support reading strategy use. Support reading strategies are defined by Mokhtari and Sheorey (2002), as "basic support mechanisms intended to aid the reader in comprehending the text" (p. 4), for example, underlining, or circling helpful information in the text, reading aloud difficult parts, note taking while reading, etc. when 9 items of Support reading strategies are closely considered, it is found that item 13 on SORS, which investigates the use of reference material when reading, is the only item which investigates the readers' interaction with ambiguous clues when reading. It is inferred that, no statistically significant relationship between AT and the Support reading strategy use of the participants is found, as these strategies are not largely concerned with the actions of the learners' which are related to their AT when reading. With respect to findings of the research question four, it is revealed that AT does not indicate a statistically significant relationship with Problem Solving reading strategy use. Mokhtari and Sheorey (2002) define Problem Solving reading strategies as "actions and procedures that readers use while working directly with the text. These are localized, and focused techniques used when problems develop in understanding textual information" (p. 4), for example, reading slowly, paying closer attention, rereading, adjusting the reading speed to the text, etc. when 8 items of Problem Solving reading strategies are closely considered, it is found that item 28 of SORS, which investigates the guessing of unknown words when reading, is the only item which investigates the readers' interaction with ambiguous clues when reading. It is inferred that, no statistically significant 
relationship between AT and the Problem Solving reading strategy use of the participants is found, as these strategies are only slightly concerned with the actions of the learners' which are related to their AT when reading. Considering that no previous studies were found to explore the relationship between AT and reading strategy use, the result of research question one to four cannot be compared. Finally, results of the study on research question five, which investigated whether any statistically significant relationship existed between participants' AT and their reading comprehension score indicated a statistically significant and positive correlation. It is implied that when ambiguity is tolerated, reading comprehension can be improved. As language learning context in general, and the activity of reading in a foreign language in particular, are abundant with novelty and ambiguous clues, it is expected that when ambiguity is tolerated reasonably, language learning and also reading comprehension be enhanced (Brown, 2000; Ely, 1989; White, 1999). As an EFL learner who is involved in reading, deals with unknown words, structures, and grammar, when such ambiguity is tolerated, the reader is predicted to achieve a better comprehension of the reading text, which interprets and confirms the finding of the current study. It is worth mentioning that, finding of the current study is in line with findings of a number of previous related studies (El-Koumy, 2000; Erten \& Topkaya, 2009; Hadiani, 2005).

\section{Conclusion}

The findings of the current study revealed that no statistically significant relationship is revealed between participants' AT and their reading strategy use; however, a statistically significant relationship is found between participants' AT and their reading comprehension scores. It means that learners with higher tolerance of ambiguity are found to have higher scores in reading comprehension. Regarding reading strategies, items on SORS were found not to be largely concerned with the actions of the learners' which are related to their AT when reading; however, these strategies aid learners improve their reading comprehension through different techniques. Hence, no statistically significant relationship was revealed between participants' AT and their reading strategy use. It can be concluded that, although AT can positively influence reading comprehension of EFL learners, it has no associations with reading strategy use of the learners, and AT seems to have other channels to direct its influence on learners' reading comprehension.

Reading skill is of a significant role in EFL learning context, regarding the large amount of input ( in the form of reading texts) to which the learners, especially in EFL contexts, are exposed during any stage of language learning. It is expected that learning a foreign or second language be facilitated by learners' improvement in reading skill. Considering AT as a learning style, which is revealed to be correlated positively with proficiency in reading, this study has implications for language teachers, to pay closer attention to the notion of AT in their class rooms. It is vital that teachers be vigilant towards ambiguous situations which deteriorate learning, and can predict or detect them and deal with them reasonably rather than trying to eliminate them. Then, the teachers need to think twice before designing activities in the classroom, or assignments, to see how much do they provide an environment appropriate to let learners discover their styles, and become aware and capable of keeping AT, in a level beneficial to his/her learning . Moreover, material developers, as providers of a large portion of the language learning setting, have a fundamental role. When reading strategy training hints or AT strengthening motives are inserted in appropriate parts of a coursebook, teachers are provided with a powerful device to optimize language learning activities, and learners can benefit a more harmonious EFL context.

\section{References}

Anderson, N. J. (2003). Scrolling, clicking, and reading English: Online reading strategies in a second/foreign language. The Reading Matrix, 3(3), 1-33. [Online] Available: http://www.readingmatrix.com/articles/anderson/article.pdf (June 6, 2011)

Brown, H. D. (2000). Principles of language learning and teaching $\left(4^{\text {th }}\right.$ ed.). New York: Pearson Education Company.

Budner, S. (1962). Intolerance of ambiguity as a personality variable. Journal of Personality, 30, 29-50. http://dx.doi.org/10.1111/j.1467-6494.1962.tb02303.x

Cohen, A. (2003). The learner's side of foreign language learning: Where do styles, strategies, and tasks meet? International Review of Applied Linguistics in Language Teaching, 41, 279-291. http://dx.doi.org/10.1515/iral.2003.013

El-Koumy, A. A. (2000). Differences in FL reading comprehension among high-, middle-, and low-ambiguity tolerance students. Paper presented at the National Symposium on English Language Teaching in Egypt. Ain Shams University, Egypt.

Ely, C. M. (1989). Tolerance of ambiguity and use of second language learning strategies. Foreign Language Annals, 


\section{2, 437-445. http://dx.doi.org/10.1111/j.1944-9720.1989.tb02766.x}

Ely, C. M. (1995). Tolerance of ambiguity and the teaching of ESL. In J. Reid (Ed.), Learning styles in the ESL/EFL classroom (pp. 87-95). Boston: Heinle \& Heinle.

Erten, I., \& Topkaya, E. (2009). Understanding tolerance of ambiguity of EFL learners in reading classes at tertiary level. Novitas-Royal, 3(1), 29-44. [Online] Available: http://www.novitasroyal.org/vol_3_1/erten_topkaya.pdf (May 4, 2010)

Farhady, H., Jafarpur, A. J., \& Birjandi, P. (1994). Testing language skills: From theory to practice. Tehran: SAMT.

Furnham, A. (1994). A content, correlational and factor analytic study of four tolerance of ambiguity questionnaires. Personality and Individual Differences, 16(3), 403-410. http://dx.doi.org/10.1016/0191-8869(94)90066-3

Kazamia, V. (1999). How tolerant are Greek EFL learners of foreign language ambiguities? Leeds Working Papers in Linguistics, 7, 69-78. [Online] Available: http://www.leeds.ac.uk/linguistics/WPL/WP1999/kazamia (April 21, 2010)

Khalifa, H., \& Weir, C. J. (2009). Studies in Language Testing, 29. Examining Reading: Research and Practice in Assessing Second Language Reading. Cambridge: Cambridge University Press.

Liu, F. (2006). Ambiguity tolerance in Chinese students of college English. Asian Social Science, 2(12), 96-99

Macaro, E. (2003). Teaching and learning a second language. London: Continuum.

Mokhtari, K., \& Reichard, C. (2002). Assessing students' metacognitive awareness of reading strategies. Journal of Educational Psychology, 94(2), 249-259

Naiman, N., Frohlich, M., Stern, H., \& Todesco, A. (1978). The good language learner. Toronto: Ontario Institute for Studies in Education. Reprinted 1996 by Multilingual Matters, Clevedon, UK.

Rubin, J. (1975). What the "Good Language Learner" can teach us. TESOL Quarterly, 9(1), 41-51. http://dx.doi.org/10.2307/3586011

Susser, B., \& Robb, T. N. (1990). EFL extensive reading instruction: Research and procedure. JALT Journal, 12(2). [Online] Available: http://www.cc.kyoto-su.ac.jp/ trobb/sussrobb.html (June 6, 2011)

Urquhart, S., \& Weir, C. J. (1998). Reading in a second language: Process, product, and practice. New York: Longman.

Vogt, W. P. (2007). Quantitative research methods for professionals. New York: Pearson/Allyn \& Bacon.

White, C. (1999). Expectations and emergent beliefs of self-instructed language learners. System, 27, 443-4157

Table 1. Correlation between Ambiguity Tolerance and Overall Reading Strategy Use

\begin{tabular}{c|c|c|c}
\multicolumn{2}{c|}{} & $\begin{array}{c}\text { Overall Reading } \\
\text { Strategy Use }\end{array}$ & $\begin{array}{c}\text { Ambiguity } \\
\text { Tolerance }\end{array}$ \\
\hline \multirow{3}{*}{$\begin{array}{c}\text { Overall Reading } \\
\text { Strategy } \\
\text { Use }\end{array}$} & $\begin{array}{c}\text { Pearson } \\
\text { Correlation }\end{array}$ & 1 & -.041 \\
\cline { 2 - 4 } & Sig. (2-tailed) & & .663 \\
\cline { 2 - 4 } & $\mathrm{N}$ & 114 & 114 \\
\hline
\end{tabular}

Table 2. Correlation between Ambiguity Tolerance and Global Reading Strategy Use

\begin{tabular}{|c|c|c|c}
\multicolumn{2}{c|}{} & $\begin{array}{c}\text { Ambiguity } \\
\text { Tolerance }\end{array}$ & $\begin{array}{c}\text { Global } \\
\text { Reading strategy } \\
\text { Use }\end{array}$ \\
\hline \multirow{4}{*}{ Ambiguity Tolerance } & Pearson Correlation & 1 & .011 \\
\cline { 2 - 4 } & Sig. (2-tailed) & & .908 \\
\cline { 2 - 4 } & $\mathrm{N}$ & 114 & 114 \\
\hline
\end{tabular}


Table 3. Correlation between Ambiguity Tolerance and Support Reading Strategy Use

\begin{tabular}{c|c|c|c}
\multicolumn{2}{c|}{} & $\begin{array}{c}\text { Ambiguity } \\
\text { Tolerance }\end{array}$ & $\begin{array}{c}\text { Support } \\
\text { Reading strategy } \\
\text { Use }\end{array}$ \\
\hline \multirow{3}{*}{$\begin{array}{c}\text { Ambiguity } \\
\text { Tolerance }\end{array}$} & Pearson Correlation & 1 & -.130 \\
\cline { 2 - 4 } & Sig. (2-tailed) & & .169 \\
\cline { 2 - 4 } & $\mathrm{N}$ & 114 & 114 \\
\hline
\end{tabular}

Table 4. Correlation between Ambiguity Tolerance and Problem Solving Reading Strategy Use

\begin{tabular}{c|c|c|c}
\multicolumn{2}{c|}{} & $\begin{array}{c}\text { Ambiguity } \\
\text { Tolerance }\end{array}$ & $\begin{array}{c}\text { Problem Solving } \\
\text { Reading strategy } \\
\text { Use }\end{array}$ \\
\hline \multirow{3}{*}{$\begin{array}{c}\text { Ambiguity } \\
\text { Tolerance }\end{array}$} & Pearson Correlation & 1 & -.004 \\
\cline { 2 - 4 } & Sig. (2-tailed) & & .968 \\
\cline { 2 - 4 } & $\mathrm{N}$ & 114 & 114 \\
\hline
\end{tabular}

Table 5. Correlation between Ambiguity Tolerance and Reading Comprehension Scores

\begin{tabular}{c|c|c|c}
\multicolumn{2}{l|}{} & $\begin{array}{c}\text { Ambiguity } \\
\text { Tolerance }\end{array}$ & $\begin{array}{c}\text { Reading } \\
\text { comprehension } \\
\text { Scores }\end{array}$ \\
\hline \multirow{2}{*}{$\begin{array}{c}\text { Ambiguity } \\
\text { Tolerance }\end{array}$} & Pearson Correlation & 1 & $.383^{* *}$ \\
\cline { 2 - 4 } & Sig. (2-tailed) & & .000 \\
\cline { 2 - 4 } & $\mathrm{N}$ & 114 & 114 \\
\hline
\end{tabular}

**. Correlation is significant at the 0.01 level (2-tailed). 